\title{
A Rare Complication of Oropharyngeal Tularemia: Pneumonia Treated with Levofloxacin
}

\author{
Orofarengeal Tulareminin Nadir Bir Komplikayonu: Levofloksasin ile Tedavi Edilen Pnömoni
}

\author{
(D) Emine ÜNAL EVREN1, (D) Hakan EVREN1, (D) Pınar TUNÇBíLEK ÖZMANEVRA² \\ 1 University of Kyrenia Faculty of Medicine, Department of Infectious Diseases and Clinical Microbiology, Kyrenia, Cyprus \\ 2 University of Kyrenia Faculty of Medicine, Department of Ear, Nose and Throat, Kyrenia, Cyprus
}

Keywords: Standard tube agglutination, lung involvement, Francisella tularensis, doxycyline, complication

Anahtar Kelimeler: Standart tüp aglütinasyon, akciğer tutulumu, Francisella tularensis, doksisiklin, komplikasyon

\section{Dear Editor,}

Tularemia is a zoonotic infection caused by Francisella tularensis ${ }^{[1]}$. It is transmitted to humans by arthropod bites, direct contact with infected animals, ingestion of contaminated food or water, and inhalation of infective aerosols. Depending on the route of acquisition, there are five clinical forms of tularemia: ulceroglandular, oculoglandular, oropharyngeal, respiratory, and typhoidal. Respiratory tularemia accounts for approximately 5\% of all tularemia cases. Pneumonia may develop either as a primary event or as a complication of other forms, most frequently typhoidal and ulceroglandular ${ }^{[1]}$. Early diagnosis and treatment of tularemia may be difficult because the clinical presentation of the disease is similar to a wide variety of acute infections ${ }^{[2]}$. Reports over the past few years suggest that tularemia has reemerged worldwide ${ }^{[3-5]}$. However, the number of cases may be underestimated due to overlapping forms and atypical clinical manifestations as well as insufficient laboratory testing ${ }^{[6]}$. Herein, we report a case of oropharyngeal tularemia with a relatively rare complication of this form: pneumonia.

A 25-year-old woman with a single kidney due to renal agenesis, presented to our clinic with a one-week history of high fever, fatigue, neck swelling, and sore throat. She was initially seen by an ear, nose, and throat specialist for these complaints. At this visit, she was given ampicillin/sulbactam therapy. She reported travel to a camping area in a rural region of Northern Cyprus (an island country in the Eastern Mediterranean located south of Turkey) one week before onset. She did not report any insect bite or consumption of possibly contaminated food or water. The patient had a fever of $39.8{ }^{\circ} \mathrm{C}$, a heart rate of 138 beats/ minute, oxygen saturation of $95 \%$, and blood pressure of $91 / 62$ $\mathrm{mmHg}$. Physical examination revealed exudative tonsillitis, a $2 \times 3 \mathrm{~cm}$ right cervical lymphadenopathy with no suppuration, and reduced breath sounds in the right lower lung.

Laboratory studies showed abnormalities such as leukocyte count of $12000 / \mu \mathrm{l}$, hemoglobin level of $8.8 \mathrm{~g} / \mathrm{dl}$, C-reactive protein level of $14.24 \mathrm{mg} / \mathrm{dl}$ (normal $0-0.5 \mathrm{mg} / \mathrm{dl}$ ), and procalcitonin level of $6.27 \mathrm{ng} / \mathrm{ml}$ (normal 0 to 0.05 ). Liver and kidney function tests were normal. Rapid streptococcal test, Epstein-Barr virus viral capsid antigen immunoglobulin $\mathrm{M}$ (IgM), Cytomegalovirus IgM, anti-Human Immunodeficiency Virus, and Weil-Felix agglutination tests were negative. There was no pathogenic bacterial growth in throat culture. Chest X-ray (CXR) showed right lower opacity and blunting of the right costophrenic angle. Thoracic computed tomography

Cite this article as: Ünal Evren E, Evren H, Tunçbilek Özmanevra P. A Rare Complication of Oropharyngeal Tularemia: Pneumonia Treated with Levofloxacin. Mediterr $\mathrm{J}$ Infect Microb Antimicrob. 2019;8:17. 
scan revealed right side posterior-basal consolidation with pleural effusion (Figure 1). In neck ultrasonography, multiple conglomerated lymphadenopathy in ovoid structure with the largest 3 centimeters on the right were observed in the bilateral cervical lymphatic chain.

The patient was hospitalized and doxycycline treatment was initiated. Three days later, hepatic enzymes increased (alanine aminotransferase: $165 \mathrm{u} / \mathrm{l}$; aspartate aminotransferase: $188 \mathrm{u} / \mathrm{l})$. Therefore, doxycycline was switched to levofloxacin. The patient was discharged with a prescription of levofloxacin for another seven days. Standard tube agglutination titers for tularemia were 1:80 positive (Quest Diagnostics, San Juan Capistrano, CA, USA) at 12 days after onset, and a four-fold rise (1:320) was observed 14 days later. Two weeks after levofloxacin treatment, the patient recovered completely. Four weeks later, follow-up CXR was normal (Figure 2). A follow-up evaluation revealed no relapse after three months.

Clinical diagnosis of tularemia can be challenging because of its rarity and difficulties in laboratory testing ${ }^{[7]}$. Since the samples are considered to be highly infectious, bacterial culture can only be performed in laboratories meeting Biosafety Level 3 criteria. Therefore, the majority of cases are diagnosed by clinical findings and serology ${ }^{[6]}$. An acute microagglutination titer of 1:128 or tube agglutination titer of 1:160 is suggestive of infection and a four-fold rise in antibody levels between acute and convalescent serum specimens is considered confirmatory ${ }^{[8]}$. Little is known about tularemia in Northern Cyprus. A single case was reported in 2017 by Uncu et al. ${ }^{[9]}$.

The ulceroglandular form has been the main presentation in cases worldwide. However, recently the oropharyngeal form has

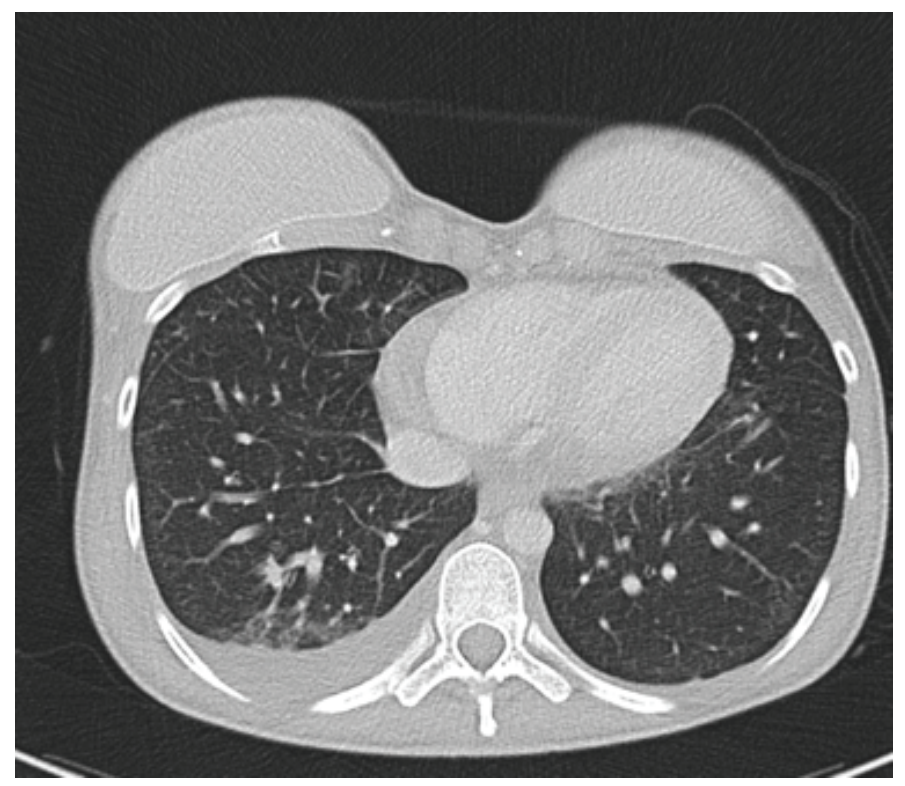

Figure 1. Thoracic computed tomography: Right side posteriorbasal consolidation with pleural effusion been seen with increasing frequency ${ }^{[1]}$. The oropharyngeal form is acquired by consuming contaminated food or water, or through the respiratory route via contaminated droplets ${ }^{[8]}$. The possible source of infection in our case is unknown. Moreover, the rest of the campers remained healthy. Patients may present with pharyngitis with or without tonsillar involvement. The disease is most often associated with unilateral lympadenopathy. These signs can easily be misinterpreted as a streptococcal infection, as in our case. However, after approximately one week of ampicillin/sulbactam treatment, the patient showed no clinical response.

Lung involvement can develop as a primary manifestation of the respiratory form, but may also appear as a complication in any form of the infection due to hematogenous spread ${ }^{[2]}$. Secondary pneumonia usually complicates the typhoidal and ulceroglandular forms. One Lousiana study found that $44 \%$ of typhoidal and $17 \%$ of ulceroglandular tularemia cases presented with pleuropulmonary disease ${ }^{[8]}$. Respiratory complications are rare in the oropharyngeal form. Primary respiratory tularemia is an uncommon form acquired from inhalation of the microorganism ${ }^{[8]}$. It is reported that patients with lung involvement are more likely to be older and to have higher mortality rates ${ }^{[1]}$. Symptoms of respiratory tularemia are nonspecific, and it is difficult to differentiate this form from other atypical pneumonia forms ${ }^{[6]}$.

Radiographic findings of pulmonary tularemia are highly variable. Some studies describe multilobar patchy opacities while others note unilobar consolidations. Pleural effusions are reported to be common $(21-32 \%)^{[8]}$. It must be kept in mind that

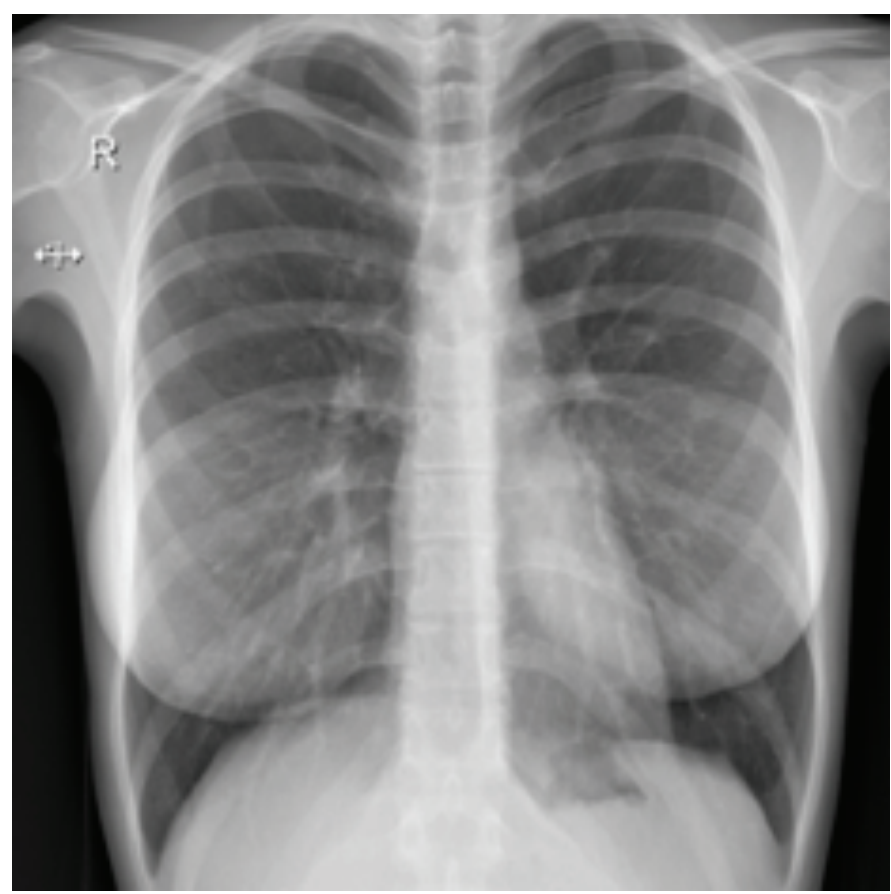

Figure 2. Repeated and normal chest X-ray 
respiratory symptoms may be absent. Our patient had no clinical signs of pneumonia despite parenchymal infiltration and pleural effusion. The differential diagnosis of oropharyngeal tularemia includes streptococcal pharyngitis, infectious mononucleosis, adenoviral infections, diphtheria, and tuberculosis. Our case was a healthcare worker, and her recent periodical examination including CXR was negative for tuberculosis.

First-line treatment for tularemia includes aminoglycosides, particularly streptomycin and gentamycin. A literature review reported no relapse in patients treated with streptomycin and a $6 \%$ relapse rate in patients treated with gentamycin. Alternative antimicrobials are tetracycline and quinolones. Tetracycline and doxycycline are bacteriostatic against F. tularensis, which may explain the higher relapse rates associated with them $(12 \%)$. Studies have reported that several cases were treated successfully with quinolones and the outcomes were similar to those treated with aminoglycosides. We did not consider streptomycin as an appropriate drug in our cause due to the presence of a single congenital kidney. Thus, doxycycline was initiated. After hepatotoxicity, we continued with levofloxacin treatment.

In conclusion, tularemia should be considered in the differential diagnosis of febrile conditions developing after outdoor activities. Clinicians practicing in rural areas should be aware of tularemia, especially in case of empirical antibiotic treatment failure.

\section{Ethics}

Informed Consent: Informed consent was obtained from the patient.

Peer-review: Externally and internally peer-reviewed.

\section{Authorship Contributions}

Surgical and Medical Practices: P.T.Ö., Concept: E.Ü.E. Design: E.Ü.E.., Data Collection or Processing: P.T.Ö., Analysis or Interpretation: H.E., Literature Search: H.E., Writing: E.Ü.E.

Conflict of interest: Authors declare that they have no conflict of interest.

Financial Disclosure: The authors declared that this study received no financial support.

\section{References}

1. Penn RL. Francisella tularensis (tularemia), in Mandell, Douglas, and Bennett's Principles and Practice of Infectious Diseases. $8^{\text {th }}$ ed. Elsevier. 2015;2590-602.

2. World Health Organization (WHO). WHO guidelines on tularaemia: epidemic and pandemic alert and response. 2007: World Health Organization. Last accessed date: 20.06.2019. Available from: https:// books.google.com.tr/books/about/WHO_Guidelines_on_Tularaemia. html?id=j6YsDwAAQBAJCtredir_esc $=y$

3. Zargar A, Maurin M, Mostafavi E. Tularemia, a re-emerging infectious disease in Iran and neighboring countries. Epidemiol Health. 2015;37:e2015011.

4. Akalin $H_{1}$ Helvaci $\mathrm{S}$, Gedikoğlu S. Re-emergence of tularemia in Turkey. Int J Infect Dis. 2009;13:547-51.

5. Kaysser P, Seibold E, Mätz-Rensing K, Pfeffer M, Essbauer S, Splettstoesser WD. Re-emergence of tularemia in Germany: presence of Francisella tularensis in different rodent species in endemic areas. BMC Infect Dis. 2008:8:157.

6. Sobolewska-Pilarczyk $M$, Pawłowska $M$, Halota W. Ulceroglandular Tularemia Complicated by Pneumonia-a case report. Przegl Epidemiol. 2014;68:421-4.

7. García RG, Serna MF, Gil MD, Villalba GC. Tularemia: A Case Report. J Infect Dis Ther. 2016;4:2332.

8. Thomas LD, Schaffner W. Tularemia pneumonia. Infect Dis Clin Nort Am. 2010;24:43-55.

9. Uncu M, Süer K, Kocaoğlu M, Şafak MA, Çağlar K. Case Report of Systemic Tularemia in Cyprus. Cyprus J Med Sci. 2017;2:81-4. 